\title{
Educação Física Escolar: o currículo como oportunidade histórica
}

CDD. 20.ed. 796.017

Walter Roberto CORREIA*

http://dx.doi.org/10.1590/1807-55092016000300831

\section{Resumo}

Considerando o atual debate sobre os currículos nacionais, o presente ensaio tem por objetivo analisar alguns aspectos didáticos de forma a contribuir para o desenvolvimento e organização do conhecimento da Educação Física Escolar.

Palavras-chave: Educação Física Escolar; Currículo; Didática.

\section{Introdução}

O presente ensaio tem por pretensão posicionar questôes relativas aos domínios dos campos da didática e do currículo da Educação Física Escolar. $\mathrm{Na}$ eminência da elaboraçáo e da divulgação da Base Nacional Comum Curricular, temos uma conjuntura muito profícua para retornarmos ao tema da relevância social dos conteúdos escolares e suas implicaçôes para docência em Educação Física no Ensino Básico. Não se insere nas objetivaçôes desse texto exaurir a temática, todavia, a intençáo do mesmo fica circunscrita em levantar questôes e direcionar algumas provocaçóes para alimentar o debate sobre o conhecimento e a especificidade do componente curricular Educação Física.

Assim sendo, o presente enredo está endereçado aos interlocutores dos campos acadêmico e profissional que se ocupam do ensino de Educação Física nos diferentes níveis de ensino e, sobremaneira, nos processos de formação inicial e continuada de professores e professoras. A premissa é a de que a legitimação de todo ou qualquer componente curricular se dá a partir da relevância social dos seus conteúdos e da consistência desses no interior da dinâmica saberes escolares, didática e currículo ${ }^{1}$.

Estudos que discutem o estado da arte e direçôes futuras em Educação Física Escolar sugerem, enfaticamente, investimentos em pesquisas didáticas para implementação de programas e currículos escolares com orientaçôes específicas aos processos de formaçáo docente ${ }^{2}$. CAPARRóz e BraCht ${ }^{3}$ analisam o tempo e o lugar da didática na Educação Física e indagam se as produçôes científicas e as políticas públicas não estariam atrofiando as discussóes didáticas e suas implicaçóes para preparação e atuação pedagógica.

Entretanto, em que pese sua inconteste presença histórica no cenário educacional, tanto a própria Educação Física como as outras áreas do conhecimento humano não dispóem de uma alocação curricular vitalícia. O próprio dinamismo da cultura e da sociedade em produzir e disseminar (desigualmente) informação e conhecimento impede que os currículos, as didáticas e os conteúdos de ensino permaneçam estáticos ou imutáveis.

Se considerarmos que as políticas públicas de currículo e educação se constituem em campos de disputas sociais, é presumível que os diferentes atores que representam as disciplinas curriculares tenham, invariavelmente, que protagonizar uma atualização de seus discursos e práticas para lograr um efetivo engajamento no currículo/projeto escolar. Dito de outra forma, os representantes dos diferentes componentes curriculares seguirão envidando esforços para justificar e legitimar suas funções educacionais/simbólicas no seio do debate das políticas públicas em educação.

Portanto, a Educação Física está inscrita no quadro contemporâneo do debate nacional. A partir da Lei de Diretrizes e Bases da Educação Nacional (LDB) e do Plano Nacional de Educação, temos como uma das pautas mais relevantes para o sistema educacional brasileiro o estabelecimento da Base $\mathrm{Na}$ cional Comum Curricular (BNCC). Esse processo tem envolvido diferentes segmentos da sociedade e 
se insere como uma das condicionantes necessárias para elevar os padróes de qualidade dos sistemas de ensino. Nesse sentido, considerando a complexidade, relevância e vitalidade desse empreendimento, o debate sobre a função social dos currículos e dos seus componentes está posto na agenda nacional e, dessa forma, a Educação Física Escolar é tema e demanda constitutiva desse processo.

Sendo assim, a observância ou a negligência das questóes didáticas na sua injunção com os currículos e programas para Educação Física Escolar podem, sem dúvidas, fomentar vulnerabilidades

\section{Desenvolvimento}

Apontar ou sugerir alguns aspectos didáticos ou metodológicos a serem considerados para uma adequação do componente curricular Educação Física é, em si, uma tentativa arriscada e não consensual. Essa tarefa tem como pano de fundo a pré-existência de uma polifonia e polissemia construídas pelas diferentes linhas teóricas e pedagógicas que constituem a Educação Física brasileira. No entanto, essa multiplicidade de concepçóes não se ancora sobre as mesmas matrizes epistemológicas/políticas que, frequentemente, se tencionam ou se contradizem mutuamente.

Aqui, como nas demais áreas do conhecimento, esses protagonismos concorrem para assumir hegemonias na educação e, em especial, no currículo escolar. Na Educação Física, sobretudo, nas últimas décadas, diferentes paradigmas, modelos ou abordagens de ensino foram elaborados e se projetaram no campo educacional. Como exemplos, temos as perspectivas desenvolvimentista ${ }^{4}$, Construtivista ${ }^{5}$, Crítico - Superadora ${ }^{6}$; Sistêmica ${ }^{7}$; Antropológica ${ }^{8}$, Crítica $^{9}$ dentre outras. Essas elaboraçóes partem de pressupostos distintos nas suas matrizes teóricas, amiúde, ainda produzem ressonâncias nos programas e currículos escolares e nos processos de formação docente.

Assim sendo, reconhecendo a vitalidade da área a partir da existência de um quadro pujante de teorias pedagógicas, interpormos algumas perguntas que julgamos fecundas, como por exemplo: como iremos mobilizar o arcabouço teórico produzido na Educação Física (Século XX) para compor os currículos escolares (Século XXI)?; Qual dessas perspectivas pedagógicas deve prevalecer?; Seria razoável supor uma perspectiva teórica/curricular específica de Educação Física que fosse capaz ou consistências para o referido componente e seus respectivos agentes. Um processo dessa natureza exigirá mais do que um posicionamento formal, demandará algum nível de "consensualidade interna/área” e, consequentemente, uma explicitação sistematizada das intençóes, formas e conteúdos escolares por parte dos seus representantes. Nesse sentido, posicionamos a seguinte questão:

Quais aspectos didáticos/curriculares poderiam ser reconhecidos para efeito de uma adequação e sistematização dos conteúdos escolares da Educação Física no Ensino Básico?

de se legitimar perante a diversidade cultural (desigualdade) da escola brasileira?; Seria admissível uma síntese didática e metodológica?; Ecletismo teórico/prático?; O componente curricular Educação Física se sustentará sem uma configuração mais prescritiva e sistematizada no atual cenário (Base Nacional Comum Curricular) de poderes instáveis - incertos - do currículo ${ }^{10}$ ? Embora relevantes, esses questionamentos ultrapassam as pretensôes desse ensaio. São provocaçóes para serem compartilhadas entre os atores sociais da Educação Física Escolar.

Diante de uma tarefa tão desafiadora e necessária, adicionamos alguns aspectos, dentre muitos, que são importantes para a restauração do debate didático e que, no nosso entendimento, são esquecidos ou negligenciados para efeito de adequação das configurações curriculares (propositivas e sistematizadas) na Educação Física, ou seja: a) especificidade da escolarização; b) especificidade dos níveis escolares; c) especificidade do componente curricular. Propor uma atenção especial, não exclusiva, no "diálogo" ou "entrecruzamento" das referidas especificidades é sugerir que as transformaçôes didáticas e pedagógicas dos conteúdos escolares pressupóem a consideração de uma visão sistêmica na busca de identidade, pertinência e sustentabilidade curricular.

\section{Retomando a questão da especificidade da escolarização}

A Educação Física Escolar é um subsistema do sistema educacional e, como tal, mantém relaçóes com a própria organicidade da educaçáo brasileira. A Constituição Brasileira ${ }^{11}$, Lei de Diretrizes e Bases Nacional ${ }^{12}$ e os Parâmetros Curriculares Nacionais ${ }^{13}$ 
nutridos pelo ideário moderno, estabelecem como finalidades fundamentais para a educação brasileira a formação para cidadania, a preparação para o mundo do trabalho e as condiçóes para o prosseguimento nos estudos posteriores. Pautadas pelos princípios da inclusão, da liberdade de pensamento e do respeito às diferenças, o sistema de ensino deve se consubstanciar por meio de programas e currículos onde as intençôes educativas devem assumir formas e conteúdos estruturados. Do ponto de vista das especificidades, talvez não seja inútil nos debruçarmos como interlocutores de área para respondermos como a Educação Física contribui com a formação da cidadania, preparação para o mundo do trabalho e formação ampla e integral dos cidadáos e cidadãs da escola.

Se o componente é subsistema de um sistema maior, suas finalidades e conteúdos devem estar imbricados e estruturados para essa dinâmica. Muitos diriam que esses pressupostos já estão dados. Será mesmo? Ainda no bojo dessa discussão, um tópico importante diria respeito se o conteúdo de ensino da Educação Física estaria sendo orientado pela especificidade da cultura escolar. Segundo SACRISTÁN e PÉrez Gomez ${ }^{14}$, a função social da escola implica num duplo processo de elaboração, ou seja, reprodução e transgressão. Ao trazermos os conteúdos para dentro dos "muros" da escola, esses mesmos devem ser submetidos a um processo de sistematização e problematização. O selecionar, o alocar, o organizar e o distribuir dos temas de ensino são, indiscutivelmente, passíveis de uma transformação didática que, nesse sentido, exige problematizações. Todos os conteúdos que justificam as disciplinas escolares existem inicialmente fora da instituição escolar (cultura) e, quando adentram, recebem um incremento didático e metodológico (cultura escolar).

No tocante à questão anterior, recorrentemente se faz diferenciaçōes entre a dança da escola com a dança na escola; o esporte da escola e o esporte na escola. Quando a dança ou esporte, por exemplo, se inscrevem como objetos da educação formal, quais são as maneiras de se explorar os conceitos, fatos, procedimentos, atitudes e valores nos diferentes ciclos de aprendizagem? Essas questôes relativas aos tipos de conhecimento e suas justificativas estão consistentemente postas nos currículos ou abordagens de ensino ${ }^{15}$ ? É uma questão superada? Se ensina a jogar, dançar e lutar na escola? Se ensina as implicaçôes sociais, políticas, biológicas, filosóficas, estéticas do jogo, da dança e do esporte na escola? O que difere um jogo dentro ou fora dos domínios da escola... e dentro ou fora da aula de Educação Física?
Prosseguindo nessa linha arguidora perguntamos: as brincadeiras populares "amarelinha", "pega-pega" ou "esconde-esconde", que incrementos recebem por dentro dos muros da escola e da Educaçáo Física que a diferem de uma atividade meramente recreativa? $\mathrm{O}$ simples fato de trazermos outras manifestaçóes das culturas "marginalizadas" e/ou "não hegemônicas" implicam, necessariamente, ampliaçáo de conhecimento e consciência crítica? Talvez os conceitos de sistematização e problematização dos saberes escolares devam retornar à pauta da reflexão didática e curricular.

Sistematizar e problematizar são processos típicos do fazer escolar e, portanto, merecem reconsideração para não ficarem sucumbidos num jogo semântico inócuo ou se assentar na luminosidade dos slogans da retórica pedagógica. A eficácia do subsistema Educação Física deve ser mediada e reavaliada na sua interação com a especificidade da educação escolarizada, pois essa é premissa da sua inserção nesse contexto. Temos observado, por vezes, a simples reprodução da cultura corporal não escolar na cultura escolar. Qual é o sentido, então, da sistematização e problematização no âmbito da Educação Física como componente ou dispositivo curricular?

\section{Retomando a especificidade dos níveis de ensino}

Outra questão possível de ser considerada diz respeito à relaçáo do componente curricular com a especificidade dos níveis de escolarização. Nesse momento, as perguntas mobilizadoras do nosso itinerário reflexivo são:

1) Como a Educação Física se relaciona com os objetivos específicos da Educação Infantil, Ensino Fundamental I, Ensino Fundamental II e Ensino Médio?;

2) Como essa disciplina "dialoga" com as outras disciplinas de modo a lograr com eficácia os objetivos do nível de escolarização e, dessa forma, ajudar o atendimento dos quesitos mais amplos do Ensino Básico?;

3) Como a Educação Física no Ensino Fundamental relaciona seus temas com o ler, escrever, interpretar, calcular, conhecimento da realidade social e política da vida dos educandos?;

4) Como a Educação Física estabelece interfaces com os objetivos gerais do Ensino Médio, na perspectiva do desenvolvimento integral do adolescente, do pensamento crítico, da conduta ética, da valorização das ciências, das artes e da literatura?

Comumente, observamos que as justificativas de interação do componente com o nível escolar 
se apoiam em alusôes genéricas de algumas características de crescimento e desenvolvimento da infância e da adolescência. Especificamente sobre essas últimas, a consistência entre teoria e prática em relação à especificidade do objeto de ensino/ aprendizagem da Educação Física tem sido moldada por uma artificial e precária retórica educativa. Os objetivos gerais do nível de ensino e a interação epistemológica dos componentes curriculares são pouco levados em conta. Os níveis de escolarização podem ser vistos como contextos socioculturais dinâmicos que demandam interfaces e comunicaçôes entre seus elementos constitutivos. Cabe numa determinada visão, construir relaçóes de sentidos nos eixos verticais e horizontais do currículo.

Tecer continuamente as "pontes" entre os objetivos específicos da disciplina com os objetivos gerais do nível de escolaridade é uma demanda para todos os docentes e áreas do conhecimento escolar. Essas interfaces e interdependências são fatores indispensáveis nos processos de justificação e legitimação dos componentes curriculares. A transversalidade tão requerida entre os campos do saber representados no projeto cultural escolar exige, sem dúvidas, uma percepçáo sistêmica dos componentes curriculares no âmbito mais amplo do projeto político-pedagógico.

Para tanto, é imprescindível que cada área ou docente tenha a compreensão da sua especificidade de forma a se situar no diálogo curricular. A falta de clareza limita a participação na esfera do trabalho coletivo o quê, por sua vez, cria uma situação de vulnerabilidade disciplinar e.... docente. $\mathrm{O}$ significado do componente tem sua validade contestada na medida que o seu objeto não tem sua relação eficazmente demonstrada na relação teoria/prática com as demais. Tomando os desafios educacionais contemporâneos, todo esforço da cultura escolar têm sido em encontrar estratégias e meios para superar a não aprendizagem e a aprendizagem mecânica na perspectiva de alcançar aprendizagens significativas e relevantes. Os componentes que não comportarem uma práxis consistente, não forjarão ou manterão adequadamente seus lugares nos "territórios curriculares". Ainda que a Educação Física Escolar advogue a "cultura corporal" ou o "se-movimentar" como identidade/especificidade, talvez essas imagens, valores ou conceitos não sejam suficientes para o currículo.

\section{Retomando a questão da especificidade da área}

A presença dos componentes curriculares se justifica a partir da relevância social das intençóes e dos seus conteúdos culturais que comportam. A pergunta feita pelos interlocutores da área se "temos o que ensinar" ainda tem sua validade no atual contexto. Mariz de Oliveira ${ }^{16}$ lançou uma provocaçáo no início dos anos noventa do século passado, perguntando se a área poderia ser comparada a um "castelo de areia", uma vez que nossos esforços não seriam fortes o suficiente para clarificar nosso objeto de ensino nas escolas e, dessa forma, ser vulnerável aos movimentos das "marés" (desmanchando completamente).

A Educação Física Escolar a partir do conceito de cultura proveniente das Ciências Humanas ampliou seus horizontes sob o ideário da "Cultura Corporal”. Sobre esse último, são diversos os seus entendimentos e aplicaçóes. Todavia, vem sendo processada uma apropriação progressiva de objetos e temas do patrimônio cultural como o Esporte, a Dança, o Jogo, a Luta, a Ginástica, o Circo e os conhecimentos sobre corpo.

A utilização da letra maiúscula para designar essas manifestaçôes culturais se dá no sentido do reconhecimento dessas como instituições históricas e sociais singulares e diferenciadas da Educação Física. A instituição Educação Física vem se apropriando historicamente e fazendo "recortes" desses conteúdos ou objetivaçóes socioculturais para ajustar às suas demandas acadêmicas e profissionais. Assim sendo, da perspectiva da Educação Física Escolar, os horizontes do componente se alargaram amplamente a partir da "riqueza" do objeto impondo desafios tanto para o currículo do Ensino Básico quanto para as formaçóes inicial e continuada de professores e professoras de Educação Física.

Exemplificando a questáo anterior, temos diante dos professores e professoras de Educação Física a incumbência de produzir um trato pedagógico de objetivaçóes culturais que incluem danças, lutas, jogos, brincadeiras, atividades circenses, modalidades esportivas, conhecimentos e cuidados sobre o corpo, ou seja, um espectro plural e incomensurável de manifestaçóes antropológicas e culturais. Essa magnitude impóe um problema, ou seja, quais são os critérios para selecionar o que ensinar, para quem ensinar, quando 
ensinar, como ensinar etc. Quais fatos, conceitos, procedimentos, valores e atitudes devem ser prioritários do ponto de vista da especificidade da Educação Física. Como avaliar esses conhecimentos? O que se enfatiza ou se omite na perspectiva curricular ${ }^{17}$ ? De forma mais direta, perguntamos: o que, o quanto e como sobre Cultura Corporal? A amplidão da Cultura Corporal e/ou da Cultura de Movimento nos remete para uma árdua tarefa de pontuar (eleger) os critérios de validação dos conhecimentos a serem elaborados pelos saberes docentes e discentes. A quem fica reservada essa tarefa ao final das contas? Esses critérios são unívocos do ponto de vista das concepçóes de ensino vigentes na área? Temos dúvidas.

Portanto, as questôes relativas à distribuição, à sequenciaçấo, à dosagem e o mapeamento curricular dos objetivos, conteúdos e métodos de ensino não são banalidades ou temas anacrônicos. Licenciandos e licenciados clamam por uma proposição mais clara desses quesitos por considerá-los elementos fundamentais de profissionalidade de suporte ao trabalho docente. O conceito de autonomia docente deve ser reconsiderado, ou melhor, resgatado do senso comum pedagógico, uma vez

\section{Considerações finais}

Recolocar a didática no debate sobre as especificidades do currículo é tarefa permanente em toda e qualquer política ou prática educativa. Discutir os critérios de organização das finalidades, objetos e meios de ensino é fundamental para a concretização dos propósitos da educação escolar por meio dos seus componentes. O campo de estudos do currículo é polimorfo e sempre será um território de não neutralidades, de disputas sociais e de relatividade histórica e cultural. Em suma, um ponto de encontro de diferentes lógicas.

No entanto, não coube nessa "heresia" dissertativa propor qualquer inovação didática, que a não instrumentalização crítica e reflexiva dessas demandas não conferem empoderamento docente e discente e, por sua vez, se torna num recurso de linguagem esvaziado de sentido.

A Educação Física Escolar tem sua trajetória marcada por ensaios propositivos não consistentemente sistematizados do ponto de vista dos conteúdos. Importante destacar que outros componentes curriculares se assemelham nessa condiçáo. Adiantamos que não ignoramos que as práticas educativas, sejam elas formais ou informais, apontam para uma concepção de sociedade, ser humano, cultura, conhecimento, escola e processo ensino-aprendizagem, A prática educativa é radicalmente política nas suas intencionalidades, meios, efeitos, juízos de valor e teleologias pedagógicas ${ }^{18}$.

Contudo, insistimos que náo se trata de uma proposta de restauração de um "didatismo tecnicista" ou "conteúdista" e, sim, de considerar que a perda de uma visão sistêmica associada a uma negligência ou absenteísmo didático/curricular comprometem, significativamente, a eficácia, a valoração e a percepção de pertinência do componente curricular Educação Física e da sua respectiva docência.

metodológica ou curricular. Mesmo admitindo o legado das abordagens ou perspectivas de ensino da Educação Física Escolar, cremos que em virtude das mesmas se circunscreverem como proposiçóes não sistematizadas ou de sistematização discutível, nos parece razoável como trabalho vindouro e oportuno, o regate das teorias de currículo e do próprio campo didático. Nossa aposta é que o atual contexto de discussão do currículo nacional é mais uma oportunidade, não uma certeza, de avanço e evolução. Se as questóes acima se constituem em falsos problemas ou dilemas, a Educação Física e seus atores o dirão! 


\begin{abstract}
School Physical Education: the curriculum as a historic opportunity

Considering the current debate on the national curriculum, this paper aims to analyze some didactic aspects in order to contribute to the development and organization of knowledge of School Physical Education.
\end{abstract}

KeY WoRDs: School physical education; Curriculum; Didatics.

\title{
Referências
}

1. Saviani N. Saber escolar, currículo e didática: problemas da unidade conteúdo/método no processo pedagógico. Campinas: Autores Associados; 1994.

2. Betti M, Dantas LEPBT, Ferraz OL. Educação física escolar: estado da arte e futuras direções. Rev Bras Educ Fís Esporte. 2011;25:105-15.

3. Caparroz FE, Bracht V. O tempo e o lugar de uma didática da educação física. Rev Bras Ciênc Esporte. 2007;26:21-37.

4. Tani G, Manoel EJ, Kokubun E, Proença JE. Educação física escolar: fundamentos de uma abordagem desenvolvimentista. São Paulo: EPU; 1988.

5. Freire JB. Educação de corpo inteiro: teoria e prática da educação física. São Paulo: Scipione; 1989.

6. Soares CL, Taffarel CNZ, Varjal E, Castellani Filho C, Escobar MO, Bracht V. Metodologia do ensino de educação física. São Paulo: Scipione; 1989.

7. Betti M. Educação física e sociedade. São Paulo: Movimento; 1990.

8. Daolio J. Educação física escolar: em busca da pluralidade. Rev Paul Educ Fís. 1996;10 Supl 2:40-2.

9. Neira MG, Nunes MLF. Educação física, currículo e cultura. São Paulo: Phorte; 2009.

10. Sacristán J. G. Saberes e incertezas sobre currículo. Porto Alegre: ArtMed; 2011.

11. Brasil. Constituição da República Federativa do Brasil. São Paulo: Saraiva; 1988.

12. Brasil. Lei de Diretrizes e Bases da Educação Nacional (LDB). Brasília: MEC; 1996.

13. Brasil. Parâmetros curriculares nacionais: educação física. Brasília: MEC; 1997.

14. Sacristán JG, Pérez Gomez A. Compreender e transformar o ensino. Porto Alegre: ArtMed; 2000.

15. Coll C. Psicologia e currículo: uma aproximação psicopedagógica à elaboração curricular. 2a ed. São Paulo: Ática; 1997.

16. Mariz de Oliveira JG. Educação física escolar: construindo castelos de areia. Rev Paul Educ Fís. 1991;5:5-11.

17. Canen A, Moreira AFB. Ênfases e omissóes no currículo. Campinas: Papirus; 2001.

18. Mizukami MGN. Ensino: as abordagens do processo. São Paulo: EPU; 1986.

\begin{tabular}{r|r} 
ENDEREÇO & \\
Walter Roberto Correia & Recebido para publicação: 01/o8/2016 \\
Escola de Educação Física e Esporte - USP & Aceito: 15/08/2016 \\
Av. Prof. Mello Moraes, 65 & \\
05508-030 - São Paulo - SP - BRASIL & \\
e-mail: wr.correia@usp.br & \\
&
\end{tabular}

836 • Rev Bras Educ Fís Esporte, (São Paulo) 2016 Jul-Set; 3o(3):831-36 